\section{Category}

Synthesis of

Materials and

Unnatural Products

\section{Key words}

diquinone-based cavitands

molecular machines

resorcin[4]arenes
I. POCHOROVSKI, M.-O. EBERT, J.-P. GISSELBRECHT, C. BOUDON, W. B. SCHWEIZER, F. DIEDERICH* (ETH ZÜRICH, SWITZERLAND AND UNIVERSITÉ DE STRASBOURG, FRANCE)

Redox-Switchable Resorcin[4]arene Cavitands: Molecular Grippers

J. Am. Chem. Soc. 2012, 134, 14702-14705.

\title{
Redox-Switchable Cavitands: Molecular Grippers
}

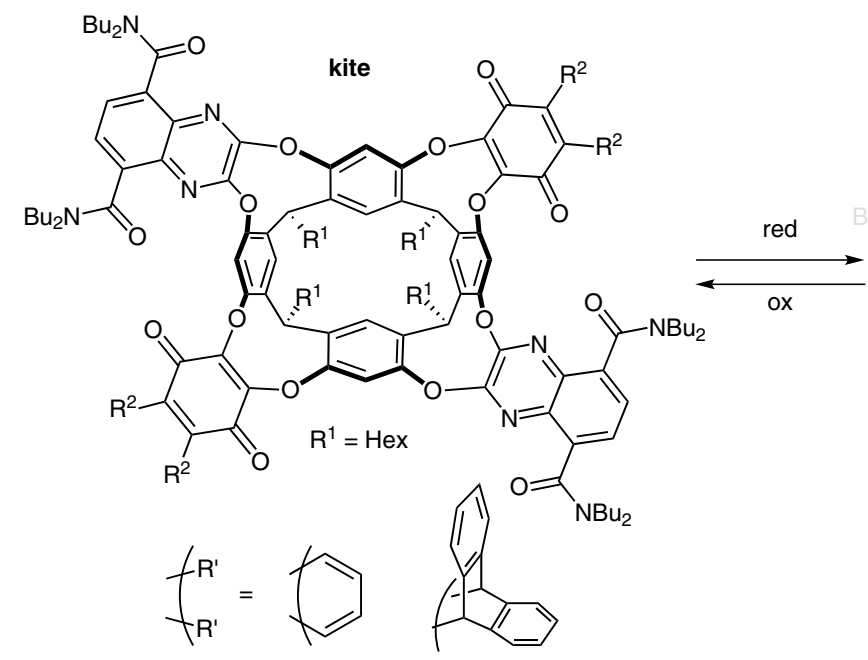
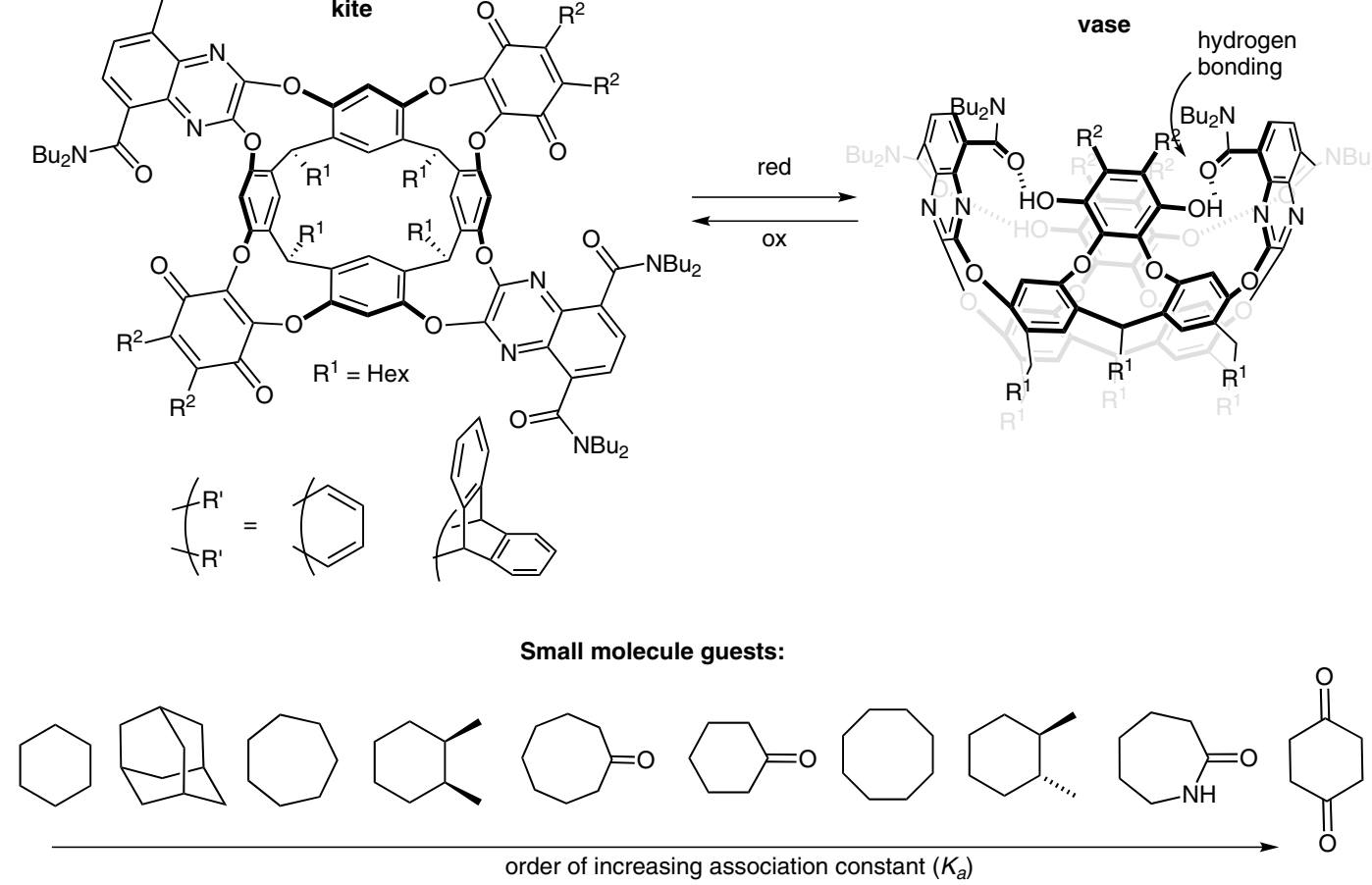

Significance: Here, a diquinone-based resorcin[4]arene cavitand goes from a kite to a vase form when reduced. The vase forms via hydrogen bonding between the central diols and the oxygens of the amides. This vase is stable even at $-80{ }^{\circ} \mathrm{C}$ and can be used to capture the small molecule guests shown above. The molecules are shown in order of increasing association constant $K_{a}$. The vase cavitand releases the guests upon oxidation.
Comment: Both the kite and vase form are stable in deuterated chloroform, tetrahydrofuran, and mesitylene. After two to four days, the reduced form reverts into the oxidized form. A crystal structure of the reduced form has a $7.3^{\circ}$ cavity, which allows it to encapsulate the solvent molecule mesitylene, as well as the larger guest molecules. 